\title{
Microbial Physiology
}

CiteScore: $\mathbf{2 . 2}$

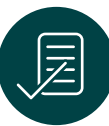

Acceptance rate $\mathbf{5 5 \%}$

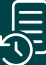

Time to first decision 33 days

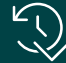

Time to final decision 9 weeks

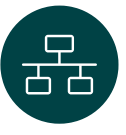

MEDLINE

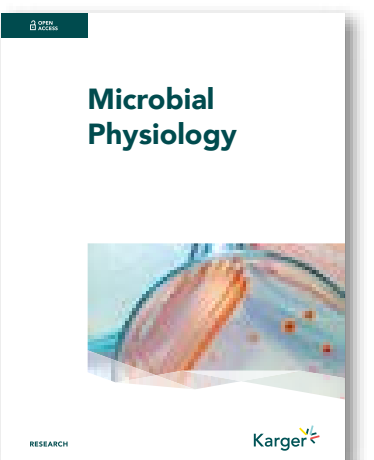

2 OPEN

ACCESS

Editors-in-Chief

Ralf Rabus (Oldenburg)

Milton H. Saier Jr. (La Jolla, CA)

\section{Reflecting the integration of basic and applied microbiology}

We are entering a new and exciting era of microbiological study and application. Recent advances in the now established disciplines of genomics, proteomics, and bioinformatics, together with extensive cooperation between academic and industrial concerns, have brought about an integration of basic and applied microbiology as never before. Microbial Physiology aims to reflect this development by publishing original research papers from all areas of microbiology and biotechnology. It also features written symposia on selected topics, timely reviews, and minireviews. Theoretical approaches and descriptions of novel, microbiologically relevant software are also considered. Contributions and ideas from large segments of the scientific community are welcome to make Microbial Physiology a viable, much needed, and up-and-coming forum for current basic and applied microbiological research.

editorialoffice_mip@ karger.com karger.com/mip 